\title{
INTERFACES ENTRE CAPS AD E JUDICIÁRIO NO CUIDADO EM SAÚDE MENTAL
}

\author{
INTERACTIONS BETWEEN CAPS AD AND \\ JUDICIARY IN MENTAL HEALTH CARE
}

\section{Tainara Oliveira Andreeti ${ }^{1}$, Douglas Casarotto de Oliveira ${ }^{2}$ e Janine Gudolle de Souza ${ }^{3}$}

\section{RESUMO}

Este artigo apresenta uma pesquisa realizada em um Centro de Atenção Psicossocial Álcool e Outras Drogas (CAPS ad). Objetivou-se compreender os efeitos da relação entre o CAPS ad e o Judiciário no cuidado em saúde mental. Além disso, o estudo buscou conhecer as principais demandas que chegam a um CAPS ad, a partir do Judiciário, e compreender as especificidades do cuidado em saúde mental, quando este é produzido na interface entre o Judiciário e o CAPS ad. Trata-se de uma pesquisa de cunho qualitativo, utilizando como instrumentos de coleta de dados diário de campo e entrevistas semiestruturadas com trabalhadores de um CAPS ad. Para tanto, a interpretação dos dados foi realizada a partir da análise de conteúdo. Os resultados demonstram que a principal demanda que chega até o CAPS ad, por meio do Judiciário, é para avaliação psiquiátrica para pedido de internação compulsória. Sendo que tal internação não tem sido utilizada apenas quando todos os recursos extra-hospitalares se tornam ineficientes. Diante disso, é preciso que todas as instituições envolvidas estejam articuladas, no que se refere ao cuidado de pessoas que fazem uso de drogas. Conclui-se que esta pesquisa contribui na compreensão da interface entre um CAPS ad e Judiciário no cuidado em saúde mental de pessoas com problemas decorrentes do uso de crack, álcool e outras drogas.

Palavras-chave: Centros de Atenção Psicossocial, Internação Compulsória, Judicialização da saúde.

\section{ABSTRACT}

This paper presents a research in a Psychosocial Care Center for Alcohol and Other Drugs (CAPS ad). The objective was to understand the effects of the relationship between CAPS ad and the Judiciary in care in mental health. In addition, the study sought to know the main demands that come to a CAPS ad, from the Judiciary, and to understand the specificities of mental health care, when it is produced at the interface between the Judiciary and the CAPS ad. This is a qualitative research, using daily field data collection instruments and semistructured interviews with workers from a CAPS ad. For this purpose, the interpretation of data was performed based on content analysis. The results demonstrate that the main demand that reaches the CAPS ad, through the Judiciary, is for psychiatric evaluation for requests for compulsory hospitalization. This hospitalization has not been used only when all extra-hospital resources become inefficient. Therefore, it is necessary that all the institutions involved are articulated, with regard to the care of people who use drugs. Concluded that this research contributes to the understanding of the interface between a CAPS ad and Judiciary in the mental health care of people with problems resulting from the use of crack, alcohol and other drugs.

Keywords: Compulsory hospitalization, Judicialization of health, Psychosocial Care Centers.

1 Psicóloga. Mestra em Psicologia (UFSM). E-mail: tainaraoandreeti@gmail.com

2 Psicólogo, mestre em Educação (UFSM) e doutorando em Psicologia Social e Institucional (UFRGS). E-mail: douglascasarotto1@gmail.com

3 Psicóloga, mestra e doutoranda em Psicologia (UFSM). E-mail: gudolle.janine@gmail.com 


\section{INTRODUÇÃO}

A Reforma Psiquiátrica brasileira tem produzido mudanças significativas na forma de conceber o cuidado em saúde mental, a partir de práticas que objetivam a reinserção social e a desconstrução de estigmas historicamente relacionados às pessoas com algum tipo de sofrimento mental. Assim, inspirada na Psiquiatria Democrática Italiana, o modelo adotado pelo Brasil, construído a partir do movimento de Luta Antimanicomial, visa mudanças técnicas e culturais, as quais se efetivarão não somente com a extinção dos manicômios e a criação de diferentes pontos de atenção no campo da Saúde, mas com intervenções em diferentes âmbitos sociais, tais como educação, trabalho, lazer, justiça, entre outros (AMARANTE, 2001).

No Brasil, a transformação do modelo hospitalocêntrico em um modelo de cuidado integral à saúde mental de base territorial ganha força com a aprovação da Lei no 10.216 , de 2001, conhecida como Lei da Reforma Psiquiátrica (RP) e com as Políticas de Saúde Mental que decorrem dessa legislação (AMARANTE, 2001). A referida lei propõe um tratamento que compreende o usuário de modo integral, como um sujeito social, com possibilidades de constituir relações de afeto. Também prevê assistência centrada no atendimento em serviços extra-hospitalares, que não separe a pessoa do seu território, além da elaboração de ações, cuja meta é a diminuição sucessiva das grandes instituições manicomiais existentes no país (AMARANTE, 2001).

Após a aprovação da Lei da Reforma Psiquiátrica, portarias têm sido criadas, a fim de regulamentar finalidade, financiamento e funcionamento de diferentes serviços extra-hospitalares, que passam a ser os responsáveis pelas ações em saúde mental. Dentre diversas portarias criadas até o momento, interessa a esse estudo a portaria 336/02 (BRASIL, 2002), que sanciona a criação de Centros de Atenção Psicossocial (CAPS), sendo esses serviços estratégicos para a organização da rede de cuidado em saúde mental (BRASIL, 2004b). O CAPS é um serviço do Sistema Único de Saúde (SUS) que funciona de maneira aberta e comunitária, sendo um lugar de referência para o tratamento de pessoas que sofrem de transtornos mentais ou problemas decorrentes do uso de crack, álcool e outras drogas, entre outros quadros que justifiquem tratamento e permanência em dispositivos de cuidado comunitários, respeitando a autonomia e promovendo vida (BRASIL, 2004b).

Tal portaria define que existem diferentes tipos de CAPS, os quais se diferenciam de acordo com critérios populacionais e também em relação à clientela a ser atendida. Existem os CAPS I e CAPS II, os quais se destinam para atendimento diário de adultos, em sua população de abrangência, com transtornos mentais severos e persistentes. O CAPS III é para atendimento diário e noturno de adultos, durante sete dias da semana, atendendo a população de referência com transtornos mentais severos e persistentes. O CAPSi é direcionado para infância e adolescência, com atendimento diário a crianças e adolescentes com transtornos mentais. Já o CAPS ad oferece atendimento diário à população com transtornos decorrentes do uso e dependência de substâncias psicoativas, como álcool e 
outras drogas. Esse tipo de CAPS possui leitos de repouso, com a finalidade exclusiva de tratamento de desintoxicação (BRASIL, 2004b).

Os Centros de Atenção Psicossocial álcool e outras drogas (CAPS ad) são os primeiros dispositivos para tratamento criados após a RP para essa finalidade. Para além da Lei da Reforma Psiquiátrica, em função das especificidades relativas ao cuidado das demandas de saúde dessa clientela, no ano de 2004, o Ministério da Saúde criou a Política de Atenção Integral a Usuários de Álcool e Outras Drogas, a qual toma como referencial teórico político para sua efetivação os conceitos de clínica ampliada, redução de danos e de trabalho em rede (BRASIL, 2004a). Assim, os CAPS ad ofertam seus atendimentos a partir de pressupostos como o cuidado territorial e a produção de redes. Usando as potências existentes no território, oferecendo atividades terapêuticas, preventivas e de promoção de saúde, as estratégias criadas pela equipe multiprofissional que atuam no serviço devem estar voltadas para a defesa da liberdade, da autonomia e da produção de um cuidado em que os sujeitos envolvidos são corresponsáveis (AZEVEDO; MIRANDA, 2010).

Após uma década da implantação dos CAPS, surgiu a necessidade de especificar os demais componentes da rede de atenção em saúde mental. Para isto, a Portaria 3.088, de 2011, do Ministério da Saúde, instituiu a Rede de Atenção Psicossocial (RAPS) para pessoas em sofrimento ou transtorno mental e com necessidades decorrentes do uso de crack, álcool e outras drogas, no âmbito do Sistema Único de Saúde (SUS). A partir da RAPS, diferentes pontos da rede de saúde mental são instituídos, os quais devem atuar conforme as diretrizes: consideração aos direitos humanos; atenção humanizada e centrada nas necessidades das pessoas; valorização da autonomia e liberdade dos sujeitos; garantia do acesso e qualidade dos serviços, ofertando cuidado integral e assistência multiprofissional, sob a lógica interdisciplinar (BRASIL, 2011).

Sendo assim, na medida em que a RP foi sancionada, o direito concebido vem acompanhado de diversas formulações de políticas que devem ser amparadas pela justiça para que sejam cumpridas. Desse modo, justiça e política não constituem campos de análise separados, pois, a partir de sua institucionalidade, concretiza-se um mecanismo de regulação social, considerando os pressupostos que sustentam a funcionalidade do controle social nas sociedades modernas, em função dos quais deve existir algum tipo de correspondência entre normas jurídicas e normas sociais (MITJAVILA, 2006).

Muitas vezes, os sistemas de saúde e saúde mental não têm sido capazes de efetivar a contento o Direito à Saúde a todas as pessoas, conforme previsão da Constituição Federal. Nessa esteira, frequentemente o Judiciário acaba sendo a última alternativa de muitos usuários para obtenção de tratamento. Segundo Brauner e Cignachi (2011), a judicialização da saúde tem trazido um grande debate, tornando-se um dos assuntos mais complexos e polêmicos, pois o aumento das ações judiciais acaba por desvirtuar, em algumas ocasiões, a destinação de recursos provenientes do governo para as áreas prioritárias de atendimento voltadas à saúde. Além disso, em relação aos serviços de saúde, essa judicialização tem gerado desconforto entre os profissionais da saúde, diante das imposições de cuidado em saúde. 
Apesar do tema da judicialização da saúde estar em voga nos últimos anos, Paixão (2019) entende que a discussão sobre tal assunto ainda carece de um aprofundamento. Em recente revisão sistemática, Freitas, Fonseca e Queluz (2020) concluem que a judicialização da saúde pode apontar para a existência de falhas na gestão e disfunções nos sistemas de saúde, tanto públicos como privados. Ainda, pode-se compreender que a judicialização da saúde está associada a uma técnica de poder, em que o Poder Judiciário, indiscriminadamente, assume o controle sobre os corpos dos indivíduos (MATTOS; RAMOS; CRUZ, 2019).

Assim, diante das problemáticas relativas à efetivação da RP e da judicialização da saúde, o presente artigo tem como principal interesse compreender os efeitos da relação entre o CAPS ad e o Judiciário 4 no cuidado em saúde mental. Além disso, o estudo busca conhecer as principais demandas que chegam a um CAPS ad, a partir do Judiciário, e compreender as especificidades do cuidado em saúde mental, quando este é produzido na interface entre o Judiciário e o CAPS ad.

\section{MÉTODO}

Esta pesquisa configura-se como qualitativa, a qual tem como proposição analisar e interpretar expressões mais profundas, oferecendo análises mais detalhadas sobre as buscas (MARCONI; LAKATOS, 2010). A pesquisa ocorreu em um Centro de Atenção Psicossocial (CAPS ad), no município de Santa Maria, no Rio Grande do Sul. O serviço desenvolve ações no campo da saúde mental, álcool e outras drogas, desde 2009. O CAPS ad possui uma equipe multiprofissional composta por enfermeiro, técnico em enfermagem, psicólogos, assistentes sociais, redutores de danos, técnicos em saúde mental, psiquiatra, recepcionista, administrativo, auxiliar de limpeza e estagiários de diferentes cursos.

Como instrumentos para coleta dos dados, foram utilizados diário de campo e entrevistas semiestruturadas. O diário de campo é uma ferramenta eficaz para quem quer compreender a prática, refletir, organizar, mudar e torná-la coerente com suas ideias (HESS, 2006). Tal instrumento foi importante para registro das relações entre CAPS ad e Judiciário, que ocorreram no cotidiano do serviço. Assim, permitiu a incorporação da experiência de pesquisa vivenciada no local de pesquisa. Já a entrevista semiestruturada foi utilizada com os trabalhadores ${ }^{5}$ atuantes no serviço, membros da equipe multiprofissional do CAPS ad. Este formato de entrevista "tem como característica questionamentos básicos que são apoiados em teorias e hipóteses que se relacionam ao tema da pesquisa” (TRIVIÑOS, 2009, p. 146).

Os critérios de inclusão para a participação nas entrevistas foram: ter idade superior a 18 anos e estar atuando no serviço por, pelo menos, seis meses. Entre os critérios excludentes estavam os trabalhadores que tivessem menos de seis meses no serviço ou que se negassem a participar da pesquisa. Ao todo, participaram seis pessoas, sendo dois homens e quatro mulheres. Entre as profissões, 
havia psicólogo, técnico em saúde mental, assistente social, redutora de danos e estagiária em Psicologia. Os participantes foram identificados em seus depoimentos pela letra ' $\mathrm{T}$ ' que é a letra inicial da palavra "Trabalhador", seguido de um número arábico, conforme a sequência de realização das entrevistas (T1, T2, T3, T4, T5, T6). Foi realizado um encontro com cada participante, com duração aproximada de uma hora.

Inicialmente, foram explicados os objetivos da pesquisa, bem como a solicitação de assinatura do Termo de Consentimento Livre e Esclarecido (TCLE). Posterior a isso, as entrevistas se deram a partir de questões norteadoras: Quais as principais demandas que chegam até o CAPS ad encaminhadas pelo Judiciário e do CAPS ad para o Judiciário? Relate uma situação ou indique algum prontuário ou documento para ilustrar a relação entre CAPS ad e o Judiciário. Que efeito tem a relação do CAPS ad com o Judiciário no cuidado das pessoas atendidas no serviço? Quando as informações se mostraram suficientes e começaram a repetir-se, foi considerado relevante não prosseguir com a coleta de dados, pois havia atingido a saturação dos dados, bem como os objetivos da pesquisa (FONTANELLA; RICAS; TURATTO, 2008). Todas as entrevistas foram gravadas e, posteriormente, transcritas na íntegra.

Para a interpretação dos dados, o material das entrevistas foi analisado a partir da Análise de Conteúdo proposta por Bardin (2009), a qual propõe três etapas: pré-análise com uma leitura flutuante do material, seguida de leitura exaustiva para organizar as informações, tornando-as operacionais e sistematizadas e, por fim, a análise das categorias estabelecidas. A partir da análise das entrevistas, foi possível organizar os dados obtidos em três categorias temáticas: "Demandando Cuidado", "Compulsando Internações" e "(Des)construindo cuidado na interface entre o CAPS ad e o Judiciário".

Esta pesquisa foi encaminhada e aprovada pela Câmara de Ensino Pesquisa e Extensão da Faculdade Integrada de Santa Maria - FISMA. A pesquisa obteve autorização do Núcleo de Ensino e Pesquisa em Saúde e do local. Após, foi cadastrada na Plataforma Brasil, sendo submetida à apreciação pelo Comitê de Ética e Pesquisa (CEP) da Universidade Federal de Santa Maria - UFSM, onde foi aprovada (CAAE: 55984716.9.0000.5346).

\section{RESULTADOS E DISCUSSÃO}

\section{DEMANDANDO CUIDADO}

Nesta categoria, são discutidas questões relativas ao cuidado demandado na interface entre CAPS ad e Judiciário, a partir da visão dos trabalhadores. Para a maioria dos trabalhadores entrevistados, a principal demanda que chega até o CAPS ad, por meio do Judiciário, é para avaliação psiquiátrica para pedido de internação compulsória. "A principal demanda é avaliação psiquiátrica, principalmente para adolescentes, para verificar se é caso de internação ou não, para a equipe avaliar 
que tipo de intervenção, se é para internação, ou seja, principalmente para internação" (T1). Semelhante relato pode ser observado na fala de outro trabalhador:

A principal demanda é avaliação psiquiátrica e ali aparece, especificamente, avaliação do médico psiquiatra para internação compulsória que, inclusive, a gente está tentando construir um novo fluxo que seja condizente com o nosso serviço que não seria para internação compulsória a priori, mas a principal demanda que toda a semana tem é consulta médica para avaliação psiquiátrica para internação (T3).

Pensando na atuação do Judiciário em relação à saúde mental, Duarte et al. (2012) destacam o pedido de internação como principal demanda atendida pela Defensoria Pública nos casos de abuso de álcool e drogas e transtornos mentais, sendo geralmente a primeira opção de tratamento, judicializando assim a saúde. Os autores salientam a importância da reflexão sobre a internação no âmbito do Poder Judiciário. Para Lara (2015), a principal preocupação do Poder Judiciário e do Ministério Público com usuários de drogas é proteger a integridade das demais pessoas do seu convívio, recuperar o sujeito e livrá-lo do vício. Porém, o que mais se enfatiza é que essa pessoa poderá cometer um mal maior e, por isso, precisa ser internada. Em nenhum momento se discute o cuidado à saúde dessas pessoas na perspectiva da redução de danos ${ }^{6}$, em que são relevantes as questões relativas à saúde dos usuários.

Moraes et al. (2019) realizaram uma pesquisa com mulheres usuárias de crack, a partir de entrevistas narrativas. As participantes do estudo reconheceram a internação compulsória como uma experiência violenta, a qual retira o sujeito do contexto no qual se encontra inserido, não havendo diálogo antes, durante ou depois da internação. Dessa forma, os autores entendem que "o diálogo possibilita a escuta do outro e do seu real desejo" (MORAES et al., 2019, p. 150), indicando a importância de uma experiência de escuta no processo de internação compulsória. Assim, torna-se fundamental espaços de escuta e diálogo, como forma de cuidado, com os sujeitos que fazem uso de drogas, levando em conta seu contexto de vida, suas relações, suas atividades cotidianas e seus saberes.

De acordo com o relato trazido pelo trabalhador, muitas vezes, o Judiciário está preocupado em cumprir algumas leis. A atuação do Poder Judiciário, em sua função maior, é de garantidor dos direitos fundamentais do indivíduo (KARAM, 2012). Ele destina-se, unicamente, a controlar a legalidade de tratamentos compulsórios, requeridos por familiares, pelo Ministério Público ou determinados por profissionais da saúde, observados os limites dados pela Lei da Reforma Psiquiátrica.

Eu entendo a demanda de judicialização de cuidado, ou seja, esse trabalho em conjunto com o Judiciário, muito voltado para adolescência, o público adolescente, mais preciso nas questões nos incisos do Estatuto da Criança e do Adolescente (ECA), amparado por essa certa vigilância do conselho para as famílias. Uma demanda de assistência psicossocial de avaliação psiquiátrica nessa questão precisa do uso da droga como maconha, crack, cocaína. Eu vejo o Judiciário com essa demanda de avaliação no CAPS perante esse tema da droga com a adolescência. Eu vejo isso como principal demanda que está mais latente (T5).

6 A redução de danos caracteriza-se como uma abordagem ao fenômeno das drogas que visa minimizar danos sociais e à saúde associados ao uso de substâncias psicoativas (BRASIL, 2005). 
As falas dos trabalhadores remetem a uma situação em que, ao acessar o CAPS por meio do Judiciário, a internação é colocada como recurso privilegiado de cuidado pelos profissionais da rede, no caso, o Conselho Tutelar. Tal forma de lidar com o cuidado do adolescente com suspeita de uso de drogas vai de encontro à própria lei de reforma, que coloca a necessidade de estabelecimento de um cuidado realizado a partir de uma rede territorializada e o próprio ECA. Em seu artigo 121, o ECA estabelece que, em nenhuma hipótese, será aplicada a internação, quando houver outra medida adequada. Nesse sentido, é necessário que haja outras intervenções antes do pedido de internação.

Esse modo de conceber o cuidado do adolescente é marcado por uma determinada forma de tratar e de falar sobre o jovem usuário de droga. Trata-se de uma prática e de uma malha discursiva que sustentam a noção de que o usuário de droga é um misto de doente e delinquente, e que a alternativa para salvar a sua vida seria uma internação-isolamento (OLIVEIRA; DIAS, 2010). Como salientam Lins, Pimentel e Uchôa (2010), o que se percebe é que devido ao grande apelo midiático em relação ao uso de crack na adolescência, as famílias, desesperadas, solicitam ao Judiciário uma internação para os jovens, embora seja uma intervenção que vai contra o que pressupõe a RP. Essa situação torna imprescindíveis ações de informação acerca da desconstrução das internações. Portanto, observa-se que a principal demanda atendida pelos trabalhadores do CAPS ad na interface com o Judiciário tem ocorrido de forma generalista, apenas solicitando avaliação psiquiátrica para internação, sem que o contexto, tanto dos profissionais quanto dos usuários, seja analisado primeiramente.

\section{COMPULSANDO INTERNAÇÕES}

Considerando o significado da palavra compulsando, pretende-se analisar, examinar cuidadosamente, enfim, compreender a problemática que cerca o tema das internações compulsórias. Observando que a principal demanda encaminhada do Judiciário para o CAPS ad é para avaliação psiquiátrica para internação compulsória, será discutida, nesta categoria, a internação compulsória, a partir da percepção dos trabalhadores entrevistados. A Lei da Reforma Psiquiátrica regulamenta a internação psiquiátrica e a divide em três modalidades, sendo elas: internação voluntária: aquela que acontece com o consentimento do usuário; involuntária: aquela que ocorre sem o consentimento do usuário e compulsória: aquela determinada pela justiça, que só será indicada quando os recursos extra-hospitalares se mostrarem insuficientes (BRASIL, 2001).

Para os trabalhadores do CAPS ad, quando o usuário chega ao serviço encaminhado pelo Judiciário com uma solicitação de avaliação para internação, esse não deve ser visto apenas a partir de sua condição de usuário de álcool e outras drogas. Ele necessita ser avaliado, a partir de uma perspectiva psicossocial, que considera as relações do sujeito, a droga e seu contexto, sendo este último composto por diferentes determinantes: familiares, socioeconômicos, culturais, institucionais. Nesse sentido, a avaliação realizada não se restringe a averiguação se há o uso de drogas ou não, mas se refere a um 
conhecimento do sujeito e suas relações, além de uma análise sobre os fatores que contribuem para sua saúde ou seu adoecimento. O trabalhador reflete sobre uma mudança no serviço para acolhimento de quem chega: "Quando o usuário chega ao serviço encaminhado para consulta para avaliação psiquiátrica a gente conseguiu estabelecer que, antes de passar na avaliação médica, a gente faz um plantão, passa pelo acolhimento [...] e faz a avaliação da real necessidade dessa internação" (T3).

Portanto, conforme a Lei da Reforma Psiquiátrica e pensando no cuidado de pessoas com problemas decorrentes do uso de álcool e outras drogas, na perspectiva da atenção psicossocial, para que seja feita uma avaliação psiquiátrica para uma internação compulsória, é necessário que se faça uma avaliação mais criteriosa da real situação do usuário. De acordo com (T4),

[...] quando a gente faz o plantão, quando a pessoa chega encaminhada pelo Judiciário, a gente conversa com o usuário e com o familiar, às vezes com o conselheiro tutelar, quando é adolescente sempre vem com o conselheiro tutelar e a gente vê se a questão da pessoa é mais relacionada a outras vulnerabilidades em função do uso abusivo de álcool e outras drogas, que esteja colocando essa pessoa em risco. E quando a gente percebe que não é essa questão, a gente conversa com o conselheiro ou com a pessoa que está aqui e conversa com o médico e diz que a gente percebeu que não há necessidade de internação no momento (T4).

Tal forma de conceber a noção de avaliação se alinha à política do Ministério da Saúde de atenção integral às pessoas com problemas decorrentes do uso de drogas, a qual coloca a clínica ampliada como referencial ao trabalho com essa demanda (BRASIL, 2004b). A clínica ampliada se propõe a realizar uma reformulação, uma reconstrução ampliada do modelo biomédico, trazendo para a prática clínica saberes provenientes da Saúde Coletiva, Saúde Mental, do Planejamento e da Gestão e das Ciências Sociais e Políticas, considerando fundamental ampliar o objeto de trabalho da clínica. Em geral, o objeto de trabalho indica o encargo, aquilo sobre o que aquela prática se responsabiliza. A Medicina tradicional se encarrega do tratamento de doenças; para a clínica ampliada, haveria necessidade de se ampliar esse objeto, agregando a ele, além das doenças, também problemas de saúde, pois são situações que ampliam o risco ou vulnerabilidade das pessoas (CAMPOS; AMARAL, 2007).

Pensando a partir de Lara (2015), pode-se perceber que uma forma de lidar com a questão das drogas se atualiza com medidas emergentes e excludentes. Nessa perspectiva, as pessoas que as usam são tomadas como bode-expiatório de questões mais amplas que são invisibilizadas, tais como violência, desigualdade social, racismo, entre outras. Podemos compreender bode expiatório como sendo aquele que é sacrificado, marcado com um signo negativo, representativo de tudo que é ruim (DELEUZE; GUATTARI, 2000). Sem dúvida, isso suscita a necessidade de um olhar e uma escuta atenta a essa população.

Pode-se observar que, geralmente, o pedido de avaliação de internação compulsória é feito desconsiderando o contexto, ou seja, colocando o uso de drogas como problema principal a priori. Uma problemática que pode ser observada, através das falas apresentadas pelos trabalhadores, é a da relativização acerca do efeito da droga em relação à pessoa atendida, no que se refere ao modo de 
compreender o papel da droga na vida do usuário e o quanto esse uso ou outros fatores são responsáveis pelo sofrimento do sujeito.

A família quando procura o Judiciário é porque está em busca de uma internação. O problema é que, na maioria das vezes, não é somente a droga que está envolvida e, sim, o contexto de vida do usuário. Exemplo disso são as internações em algumas comunidades terapêuticas, onde, na maioria das vezes, o que é enfatizado é o uso (T6).

A seguir, é apresentado um caso de um adolescente levado ao CAPS para avaliação para internação compulsória em que, a partir de algumas práticas, o uso de drogas sai do centro da problemática e outras questões de cuidado emergem:

Era uma manhã de quinta-feira, por volta das 9:30. Chega ao CAPS um menino adolescente, 15 anos, R.A., acompanhado de um conselheiro tutelar e seu irmão, com um documento judicial pedindo avaliação psiquiátrica para uma internação. Como eu estava atuando como estagiária no Plantão de $\mathrm{PTS}^{7}$, foi então que atendi, junto com um profissional do CAPS, o adolescente R.A. e seu irmão. O menino relatou que fazia uso esporadicamente de maconha. O irmão de R.A. disse que se surpreendeu quando a outra irmã procurou o Judiciário para pedir uma internação para o menino, pois relatou que o menino é calmo e não costuma causar problemas para a família e que, inclusive, desde os 11 anos de idade, ajuda no cuidado com a mãe que tem as duas pernas amputadas. R.A. ajuda desde a higiene até a alimentação. O menino relatou ter alguns conflitos com o pai que é etilista e chega em casa depois do trabalho bastante agressivo. Após avaliar a situação do menino e do uso não ser frequente, entendemos que não havia necessidade de uma internação no momento. Mas que esse caso precisava de alguma intervenção. Foi então decidido, junto com o psiquiatra, que no momento R.A. iria receber uma vez por semana, em sua casa, a visita de um Acompanhante Terapêutico (AT), para avaliar melhor a situação. O psiquiatra também receitou uma medicação para ansiedade para o menino, que relatou não conseguir dormir e, por isso, usava maconha, mas sempre reforçando que o uso não era frequente (Notas do Diário de Campo).

Dias depois, atuando como AT, passei a ir à casa do menino. Comecei a observar os diversos conflitos que a família tinha, inclusive com questões econômicas. A irmã passou a relatar que o problema não era mais R.A. e, sim, o pai do menino que havia perdido o emprego por ser etilista e estar ingerindo substâncias no horário de trabalho e também que R.A. havia arrumado um emprego e que estava sustentando a família neste momento (Notas do Diário de Campo).

É preciso, muitas vezes, entender que o cuidado está para além do uso de drogas, não que o uso não tenha que ser considerado, mas segundo o caso relatado no diário de campo, pode-se observar que houve algumas situações importantes relativas à vida do adolescente que não estavam sendo consideradas. Uma questão evidenciada foi a falta de intervenção do Conselho Tutelar, em relação ao fato de um menino de 15 anos não estar estudando, mas apenas trabalhando para ajudar a família nas questões financeiras. Outra questão é que, conforme a Lei da Reforma Psiquiátrica, a internação só

7 Projeto Terapêutico Singular (PTS) é o conjunto de propostas que visa o cuidado do indivíduo por meio de condutas terapêuticas articuladas e direcionadas às suas necessidades individuais ou coletivas, como, por exemplo, no grupo familiar (BRASIL, 2009). 
deve ocorrer quando todos os recursos se tornarem insuficientes. Nesse caso, nenhum recurso havia sido buscado. Foi diretamente para o Judiciário e, então, foi pedida a avaliação para uma internação.

Os trabalhadores deixaram claro, durante as entrevistas, que não são contra a internação, mas, sim, ao modo como esta geralmente vem sendo conduzida pelo Judiciário, como forma de punição, como primeira opção de cuidado, não preconizando o que diz a Reforma Psiquiátrica. Portanto, alguns trabalhadores relataram casos em que a internação é indicada e se mostrou efetiva para o cuidado. Para T4, “em alguns casos, é necessária uma internação, até pela questão de vulnerabilidade ou pela questão da debilidade física da pessoa, que está em um uso contínuo. Então a equipe avalia que, sim, é necessária uma internação".

Já tivemos casos que avaliamos ser, sim, para a internação e, inclusive, já tivemos casos que conseguimos construir um vínculo com o usuário, a partir do encaminhamento do Judiciário. Avaliamos a pessoa e concordamos que ela necessitava de internação naquele momento e, inclusive, ela foi para a internação de forma voluntária e não compulsória (T5).

Pode-se pensar que, na internação compulsória, o sujeito que usa drogas acaba se sujeitando a um desejo de "cura", mesmo sem vontade de realizar um tratamento. Partindo deste pressuposto, a internação não pode acabar se tornando uma pena, na qual o sujeito que usa drogas é considerado um delinquente e alguém que quebrou as regras impostas pela sociedade. Sendo que, ao sair da internação, o sujeito deve voltar a seguir as normas da sociedade. Mas, sim, a internação compulsória deve ser entendida como uma das formas possíveis de internação, preconizando sempre a RP, que determina que seja realizada a internação compulsória apenas quando todos os recursos se tornarem ineficientes. Assim, “a internação compulsória constitui um recurso de exceção (risco iminente de morte) e não uma regra no manejo do uso prejudicial e dependente de substâncias” (BASTOS, 2019, p. 3).

\section{(DES)CONSTRUINDO CUIDADO NA INTERFACE ENTRE O CAPS AD E O JUDICIÁRIO}

Refletindo, então, a partir das falas dos trabalhadores entrevistados, existe alguma produção de cuidado nessa interface do CAPS ad e o Judiciário?

Acredito que sim, porque muitas vezes chega para o CAPS e não é caso para o CAPS ad, talvez seja válido para a gente ter um olhar e redirecionar o adolescente. Só que tem uma questão do Judiciário que a equipe vem discutindo há algum tempo que o Judiciário não escuta o que o CAPS avalia, porque muitas vezes a gente avalia que o adolescente não precisa de uma nova internação, que ele precisa ser responsabilizado pelos atos cometidos e o Judiciário não faz o que deveria fazer, mandar para alguma medida mais punitiva ou socioeducativa e acaba vindo outra solicitação judicial de internação. Então acaba sendo recorrente [...] (T1).

Praticamente nenhum. Claro que, muitas vezes, o usuário se vincula no serviço, mas o que realmente parece é que o Judiciário quer é se livrar daquela demanda e encaminha para cá, sem muitas vezes avaliar o caso. Então, o encaminhamento do Judiciário praticamente não produz nenhum cuidado, até porque nem conhece o trabalho do CAPS (T2). 
Apesar de ser uma questão direcionada especificamente aos trabalhadores, o cuidado produzido entre CAPS ad e Judiciário ocorre em uma relação que é vista de diferentes formas pelos profissionais. Mas os participantes remetem a uma relação em que há pouca permeabilidade do Judiciário para a avaliação realizada pelo CAPS, quando a mesma não se direciona à internação. O trabalhador (T2) considera o cuidado produzido nessa interface como negativo, destacando que é uma relação em que não há conhecimento pelo Judiciário acerca da política de saúde mental ou das perspectivas que fundamentam o trabalho do CAPS, o que ocasiona um encaminhamento mecânico.

A situação apontada pelos trabalhadores ganha detalhes no relato acerca de um caso atendido nessa interface:

Nós tínhamos uma usuária que já vinha bastante tempo no serviço, desde que era gestante, e a gente já conseguia fazer uma leitura do cotidiano da dinâmica dela. E ela não era uma usuária que ficaria vindo tal e tal dia. Que ela poderia ficar tempos sem vir no CAPS, mas que ela retornaria. E todos os familiares eram envolvidos com uso e venda de drogas. Em uma das relações dela, ela se envolveu com uma pessoa do crime, que estava agredindo ela. Inclusive, colocou fogo na casa e nós fomos tentar fazer uma visita domiciliar para ela, para ver como ela estava, porque ficamos sabendo que ela estaria grávida e que ele estava fazendo cárcere privado dela. No dia da visita, ele ameaçou a equipe, me ameaçou. Ele disse que não íamos entrar para fazer a visita. Nós fizemos relatório para o Judiciário, orientamos a mãe que procurou o CAPS, dizendo que no dia que tentamos fazer a visita ela apanhou a noite inteira. Era muito grave o caso. Fizemos relatório de tudo que estava ocorrendo, até para poder acionar a polícia, a Brigada. Esse caso de toda a situação detalhadamente para poder acionar outros dispositivos. Mas o que aconteceu é que, nesse meio tempo, surgiu uma internação compulsória, um afastamento e busca desse cônjuge de perto dela. Aí chegou um oficial de justiça no CAPS, dizendo que a gente que tinha que fazer isso num momento que a gente não poderia e não pode receber nenhum documento, sem antes passar pela Secretaria Municipal de Saúde (SMS). Porque quem responde por nós é a secretaria e não houve esse entendimento. Falaram que a gente estava se negando a buscar, sendo que não é nosso papel e iríamos só com o oficial de justiça e conselheira. Como que iríamos chegar e dizer: "fulana, tu tem que sair daí", sendo que o cara, o cônjuge, já tinha ameaçado a gente e ela mesmo disse: "deixa assim". E ia romper com o vínculo, porque não é nosso papel buscar e prender e dizer o que tem que ser feito e nos colocando em risco. Esse é um caso que a promotora, na época, nos chamou e uma série de processos surgiu com o nosso nome, como se a gente tivesse sido negligente. Ninguém olhou para o nosso lado. E nossa segurança, o cuidado com os profissionais e também o cuidado com o vínculo que foi que a gente explicou e, inclusive, surgiu uma frase: "se vocês têm medo, vocês não têm que trabalhar no CAPS". E isso marcou muito eu e minha colega. A partir disso, nós começamos a tensionar de ter audiências para poder explicar como que deveria ser um fluxo, a partir de todas as atribuições de um CAPS. E não quererem inventar uma coisa que não exista e uma coisa que vai em contato com os princípios e diretrizes pensando nesse cuidado (T3).

A situação descrita pelo trabalhador mostra que diferentes aspectos relativos ao cuidado foram negligenciados pela forma como a promotoria e o oficial de justiça conduziram o caso. Em primeiro lugar, foi atribuída ao CAPS uma tarefa que legalmente não é atribuição do serviço, que é a de atuar em um conflito como agentes que retirariam a moça da situação de cárcere privado. Apesar do vínculo, 
o das profissionais com a usuária, o qual facilita um acesso a certos usuários, no caso relatado havia uma solicitação explícita da usuária de não intervir na situação, sendo que, terapeuticamente, uma intervenção dessa equipe poderia comprometer o vínculo. Outra situação, não levada em conta pelo Judiciário, foi o risco às profissionais, as quais já haviam sido ameaçadas pelo companheiro da usuária.

Ainda, manifesta-se uma compreensão acerca do trabalho em CAPS como se o trabalhador tivesse o dever de se expor a situações de risco físico. Também houve uma desconsideração acerca das hierarquias existentes no serviço público, em que os trabalhadores haviam sido orientados a não receber documentos de outros setores, sem que o mesmo passasse pela SMS. Assim, por mais que se trate de um caso específico, tal relato ilustra aspectos da relação CAPS e Judiciário que, caso não se altere, pouco colaboram para a produção do cuidado. Fica evidente o quanto, além da usuária apresentada que estava em cárcere privado, as profissionais sentiram-se fragilizadas em sua potência de atuar.

Para a produção de efeitos positivos no cuidado em saúde mental na interface entre CAPS e Judiciário, é necessário que ambas as instituições se aproximem e dialoguem sobre um fluxo, conforme a fala do trabalhador, que determine como vai funcionar esse cuidado. A fim de potencializar o cuidado produzido na interface entre CAPS e Judiciário, torna-se imprescindível um entendimento acerca das técnicas de conversação utilizadas para “tecer" essa rede. Teixeira (2004) chama a atenção para a virtude dos processos micropolíticos operando no encontro trabalhador e usuário, trabalhador e trabalhador, quando as conversas acolhem, se conectam uma conversa na outra, um espaço no outro, articulando redes e constituindo espaços coletivos de conversação. A técnica de conversa define a dimensão pragmática do encontro, os domínios de ação (emoções, afetos) e de significação (linguagem, conhecimento) e as utilizações possíveis do próprio encontro.

O Judiciário nos aciona para tentar fazer um cuidado compartilhado. Infelizmente, na prática, isso se dá muito fragilmente, porque a relação física, a relação de proximidade física com o Judiciário e outras instâncias ela não se dá muito no cotidiano. Ela se dá muito pelos autos dos relatórios e isso é uma prática muito da burocracia, do cotidiano da burocratização, mas eu não sou contra a judicialização, mas eu sou contra pensar que relatório é cuidado, pensar que a emissão de relatório é cuidado (T5).

Esta fala ilustra com clareza um encontro entre Judiciário e CAPS ad que acontece por via de burocracia, em que a técnica de conversa é um documento solicitando avaliação ou um relatório enviado ao Judiciário. Tal situação, na perspectiva do trabalhador, não implica em cuidado. Buscando alternativas a essa forma de relacionar os serviços e o Judiciário, os trabalhadores trazem uma proposta que tem sido discutida. Refere-se a uma iniciativa da Gestão, em nível de Estado, de propor a formalização de um fluxo que leve em conta as especificidades dos dois pontos da rede.

a Coordenadoria Regional de Saúde trouxe uma proposta de fluxo e nós debatemos. Vamos discutir em reunião e propor conversar com o Judiciário, com o Conselho Tutelar e Assistência Social, porque é um trabalho em rede, até pode ser avaliado no CAPS, o que não pode é sair daqui a decisão se é compulsória ou não, para não romper esse vínculo (T3). 
Outro aspecto que emerge no cuidado produzido na interface Judiciário e CAPS ad é a função do Judiciário em assegurar o cumprimento da legislação. Apesar da legitimação do SUS e da Reforma Psiquiátrica via legislação específica, a efetivação na prática de cuidados em saúde mental não tem sido realizada de forma tão rápida, conforme as demandas da população. Afinal, para a efetivação do modelo de saúde preconizado pelo SUS e o de cuidado em saúde mental preconizado pela RP, diferentes são os fatores a serem modificados na forma de funcionamento do país, que vão desde o financiamento do Sistema à qualificação dos profissionais para atuar, entre outras necessidades.

O Judiciário produz certa continência. Dá um contorno para que os serviços de saúde, o CAPS, tenham noção de que certas políticas precisam ser asseguradas. [...] O Judiciário tem instâncias que trabalham juntas com ele que podem nos dar apoio, acionar no momento em que eles veem uma dessas instâncias sociais que têm condições de dar um respaldo ao CAPS (T5).

Diante dessa defasagem entre o que indicam as legislações, o serviço que é ofertado ao usuário e as demandas contemporâneas de cuidado, em muitos momentos, o Judiciário é convocado a atuar visando assegurar o cumprimento da legislação.

\begin{abstract}
O Judiciário fomenta a rede pública. Eu não vejo com maus olhos isso. Acredito que não é o Judiciário que tem que dizer o que nós da saúde temos que fazer. Um promotor falou que não é o papel do Judiciário fazer essa avaliação, quem tem que saber fazer política pública de saúde não é o Judiciário e, sim, nós da saúde. O Judiciário é um órgão fiscalizador. Se não está funcionando algo na saúde, o Judiciário pode ser fomentador desse processo de discussão, mas quem tem que acertar isso é os gestores da saúde. O que acaba sendo muito pertinente, porque se critica o Judiciário, mas não se avalia o porquê acaba tudo no Judiciário e se acaba tudo no Judiciário é porque, muitas vezes, nós não conseguimos fazer nosso serviço direito, por uma série de atravessamentos. Quanto mais falhas tiver na saúde, mais vai afunilar na boca do Judiciário, porque as pessoas não vão ser atendidas e elas vão procurar o Judiciário. Só que isso fica tão normalizado que fica comum ir para o Judiciário, desde medicação, internação, entre outros (T6).
\end{abstract}

Compreende-se que a prática de cuidados em saúde mental não tem ocorrido de forma tão rápida, conforme as demandas da população. Portanto, o Judiciário serve como um fomentador para a rede pública de saúde, para que novas estratégias de cuidado sejam criadas ou repensadas. Mas a judicialização da saúde, do modo como vem sendo desenvolvida, se não tratada de maneira adequada, pode gerar prejuízos, não só aos usuários diretamente, mas também ao Estado, pelo desvio do orçamento público ou, inclusive, por uma desestruturação do sistema público de saúde.

\title{
CONSIDERAÇÕES FINAIS
}

Esta pesquisa teve como objetivo compreender os efeitos da relação entre o CAPS ad e o Judiciário no cuidado em saúde mental. Ainda, buscou investigar as principais demandas que chegam a um CAPS ad, 
a partir do Judiciário, e compreender as especificidades do cuidado em saúde mental, quando este é produzido na interface entre o Judiciário e o CAPS ad. Foi possível compreender, a partir das entrevistas, que a principal demanda atendida pelo CAPS ad na interface com o Judiciário é para internação compulsória, e que a relação entre CAPS ad e Judiciário encontra-se fragilizada devido à falta de comunicação, necessitando de uma urgente reorganização em ambos os processos de trabalhos. Além disso, os entrevistados argumentam que um diálogo para determinar um novo fluxo de encaminhamentos do Judiciário para o CAPS ad já poderia amenizar os conflitos. Evidencia-se também que, para que aconteça uma internação compulsória, conforme principal demanda encaminhada do Judiciário para o CAPS, esta deve ser preconizada a partir da Reforma Psiquiátrica Brasileira, considerando o usuário e seu contexto social, econômico, cultural, familiar e, principalmente, sendo utilizada como último recurso.

Observou-se que a maioria dos pedidos de avaliação para internação compulsória do Judiciário para o CAPS ad é feita desconsiderando o contexto de vida dos usuários, apenas considerando o uso de drogas. Percebeu-se também que pode haver falta de informação com relação aos pontos da rede de atenção à saúde, bem como sobre as outras formas de cuidado à saúde de pessoas com problemas decorrentes do uso de crack, álcool e outras drogas. Assim, os familiares, muitas vezes, não sabem o que fazer, buscando, assim, o recurso da internação compulsória diretamente no Judiciário, na tentativa de solucionar seus problemas. Nesse sentido, é de suma importância o investimento na articulação dos serviços de saúde com os demais setores, buscando uma parceria intersetorial, como na educação, na justiça, na cultura.

Considera-se que, diante da defasagem entre o que indicam as legislações, o serviço que é ofertado ao usuário e as demandas contemporâneas de cuidado, em muitos momentos, o Judiciário é convocado a atuar visando assegurar o cumprimento da legislação e servindo também como um fomentador de políticas públicas de saúde. Durante o desenvolvimento deste estudo, percebeu-se também que os trabalhadores, por vezes, se deparam com situações que não conseguem dar resposta para o Judiciário, pois a demanda de saúde mental ocorre de maneira singular e exige uma avaliação no contexto geral de vida das pessoas, não podendo, muitas vezes, se ajustar ao tempo do Judiciário. Esse descompasso pode ser explicado, tendo em vista algumas particularidades do serviço, como falta de carro para fazer visitas domiciliares, sobrecarga de trabalho e poucos profissionais atuando no serviço.

Diante dessa conjuntura, é preciso que todas as instituições envolvidas estejam articuladas, no que se refere ao cuidado de pessoas que fazem uso de drogas. É necessário criar encontros dialógicos, em que todos possam ser ouvidos, principalmente a peça principal desse cenário, o usuário de drogas, pois é sobre seu cuidado que se está discutindo. Para a conformação de Políticas Públicas voltadas para essas pessoas é imprescindível que todos os atores sociais estejam envolvidos na busca pelo cuidado que precisamos. Este estudo contribui para uma reflexão acerca da interface entre CAPS ad e Judiciário, e entende-se que também possa repercutir em novas pesquisas voltadas às necessidades do usuário, a partir de seu contexto social, com vistas a desenvolver um cuidado integral e compartilhado. 


\section{REFERÊNCIAS}

AMARANTE, P. Loucos pela vida: a trajetória da Reforma Psiquiátrica no Brasil. Rio de Janeiro: Fiocruz, 2001.

AZEVEDO, D. M.; MIRANDA, F. A. N. Práticas profissionais e tratamento ofertado nos CAPS ad do município de Natal-RN: com a palavra a família. Escola Anna Nery Revista de Enfermagem, v. 14, n. 1, p. 56-63, jan./mar. 2010. Disponível em: https://bit.ly/3cKKZ0q. Acesso em: 02 set. 2020.

BARDIN, L. Análise de Conteúdo. Lisboa: Edições 70, LDA, 2009.

BASTOS, F. I. Políticas de drogas no Brasil contemporâneo: aportes da ciência, da clínica e do liberalismo moderno. Cadernos de Saúde Pública, Rio de Janeiro, v. 35, n. 11, e00125519, 2019. Disponível em: https://bit.ly/2PdbALi. Acesso em: 30 ago. 2020.

BRAUNER, M. C. C.; CIGNACHI, J. C. B. O direito à saúde e o papel do poder judiciário: uma perspectiva acerca das dimensões constitucionais e das tutelas coletivas. JURIS, Rio Grande, v. 16, p. 29-48, 2011. Disponível em: https://bit.ly/3c2xPgd. Acesso em: 03 set. 2020.

BRASIL. Lei n 10.216 , de 6 de abril de 2001. Dispõe sobre a proteção e os direitos das pessoas portadoras de transtornos mentais e redireciona o modelo assistencial em saúde mental. Diário Oficial da União, Brasília: Ministério da Saúde, 2001.

. Ministério da Saúde. Política do Ministério da Saúde para Atenção Integral aos usuários de álcool e outras drogas. 2. ed. Brasília: Ministério da Saúde, 2004a.

. Saúde mental no SUS: os Centros De Atenção Psicossocial. Ministério da Saúde. Secretaria da Atenção à Saúde, Departamento de Ações Programáticas Estratégicas. Brasília: Ministério da Saúde, 2004b.

. Saúde na escola. Ministério da Saúde. Secretaria de Atenção à Saúde. Departamento de Atenção Básica. Brasília: Ministério da Saúde, 2009.

. Portaria n. ${ }^{\mathrm{o}}$ 1.028/GM, de $1^{\mathrm{o}}$ de julho de 2005. Determina que as ações que visam à redução de danos sociais e à saúde, decorrentes do uso de produtos, substâncias ou drogas que causem dependência, sejam reguladas por esta portaria. Diário Oficial da União, Brasília, 2005. 
. Portaria $n^{\circ} 3.088,2011$. Institui a Rede de Atenção Psicossocial para pessoas com sofrimento ou transtorno mental e com necessidades decorrentes do uso de crack, álcool e outras drogas, no âmbito do Sistema Único de Saúde. Diário Oficial da União, Brasília, 2011.

Portaria $n^{\mathrm{o}} 336,2002$. Define e estabelece diretrizes para o funcionamento dos Centros de Atenção Psicossocial. Diário Oficial da União, Brasília, 2002.

CAMPOS, G. W. de S.; AMARAL, M. A. do. A clínica ampliada e compartilhada, a gestão democrática e redes de atenção como referenciais teórico-operacionais para a reforma do hospital. Ciência \& Saúde Coletiva, Rio de Janeiro, v. 12, n. 4, p. 849-859, ago. 2007. Disponível em: https://bit.ly/2QeKJiA. Acesso em: 02 set. 2020.

DELEUZE, G.; GUATTARI, F. Mil platôs - capitalismo e esquizofrenia. Rio de Janeiro: Editora 34, 2000.

DUARTE, C. G. et al. Internação psiquiátrica compulsória: A atuação da Defensoria Pública do estado de São Paulo. Revista da Defensoria Pública, v. 5, n. 1, p. 157-182, 2012. Disponível em: https:// bit.ly/38XGZbW. Acesso em: 01 set. 2020.

FONTANELLA, B. J. B.; RICAS, J.; TURATO, E. R. Amostragem por saturação em pesquisas qualitativas em saúde: contribuições teóricas. Cadernos de Saúde Pública, Rio de Janeiro, v. 24, n. 1, p. 17-27, jan. 2008. Disponível em: https://bit.ly/3126zIp. Acesso em: 27 ago. 2020.

FREITAS, B. C.; FONSECA, E. P.; QUELUZ, D. P. A Judicialização da saúde nos sistemas público e privado de saúde: uma revisão sistemática. Interface, Botucatu, v. 24, e190345, 2020. Disponível em: https://bit.ly/3cTu4J0. Acesso em: 02 set. 2020.

HESS, R. Momento do diário e diário dos momentos. In: SOUZA, E. C.; ABRAHÃO, M. H. M. B. (orgs.). Tempos, narrativas e ficções: a invenção de si. Porto Alegre: EDIPUCRS, 2006.

KARAM, M. Internações: aspectos jurídicos, políticos e sua interface com a saúde mental. In: Drogas, Direitos Humanos e Laço Social. Conselho Federal de Psicologia. Brasília: CFP, 2012.

LARA, P. M. Internação compulsória e o cuidado de pessoas que fazem uso de crack. 2015. Dissertação (Mestrado em Psicologia). Universidade Federal de Santa Maria - UFSM, Santa Maria, 2015. 112p. 
LINS, J.; PIMENTEL, P.; UCHÔA, R. Sobre Drogas e Redução de Danos - o cotidiano dos profissionais de saúde no programa + Vida do Recife. Recife, 2010.

MARCONI, M. A.; LAKATOS, E. M. Fundamentos da metodologia científica. 7. ed. São Paulo: Atlas, 2010.

MATTOS, D.; RAMOS, E.; CRUZ, S. A. A judicialização da saúde e a gestão biopolítica da vida: O Poder Judiciário e as estratégias de controle do sistema de saúde. Revista Direito e Práxis, Rio de Janeiro, v. 10, n. 3, p. 1745-1768, jul./set. 2019. Disponível em: https://bit.ly/3vSGUAa. Acesso em: 31 ago 2020.

MITJAVILA, M. R. Perícia técnica e arbitragem social: o caso do serviço social na área criminal do poder judiciário de Santa Catarina. Relatório técnico de pesquisa CNPq. Brasília, 2006. 123p.

MORAES, M. E. F. et al. Consumo de crack, Mulheres e Internação Compulsória: reflexões sobre saberes à luz da teoria das representações sociais. Psicología, Conocimiento y Sociedad, v. 9, n. 1, p. 132-154, mai. 2019. Disponível em: https://bit.ly/3eTW6a4. Acesso em: 02 set. 2020.

OLIVEIRA, D. C; DIAS, M. H. Os jovens usuários de crack e a rede de cuidados: problematizações a partir de uma experiência. In: SANTOS, L. M. B. (Org.). Outras palavras sobre o cuidado de pessoas que usam drogas. Porto Alegre: Conselho Regional de Psicologia do Rio Grande do Sul, 2010. p. 27-42.

PAIXÃO, A. L. S. Reflexões sobre a judicialização do direito à saúde e suas implicações no SUS. Ciência \& Saúde Coletiva, Rio de Janeiro, v. 24, n. 6, p. 2167-2172, jun. 2019. Disponível em: https:// bit.ly/3f1v4NZ. Acesso em: 03 set. 2020.

TEIXEIRA, R. R. As redes de trabalho afetivo e a contribuição da saúde para a emergência de uma outra concepção de público. Working-paper apresentado na Research Conference on: Rethinking "the Public" in Public Health: Neoliberalism, Structural Violence, and Epidemics of Inequality in Latin America Center for Iberian and Latin American Studies University of California. San Diego, 2004.

TRIVIÑOS, A. N. S. Introdução à pesquisa em Ciências Sociais: a pesquisa qualitativa em educação. São Paulo: Atlas, 2009. 
